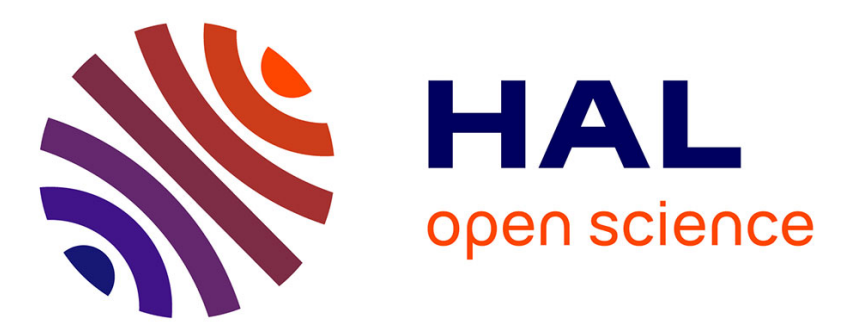

\title{
Acoustic Resonance Characterization and Numerical Model Including Acoustic Streaming in an HPS Lamp
}

Areski Toumi, Labo Chhun, Sounil Bhosle, Georges Zissis, Pascal Maussion, Benedict Baumann, M Wolff

\section{- To cite this version:}

Areski Toumi, Labo Chhun, Sounil Bhosle, Georges Zissis, Pascal Maussion, et al.. Acoustic Resonance Characterization and Numerical Model Including Acoustic Streaming in an HPS Lamp. IEEE Transactions on Industry Applications, 2013, vol. 49, pp. 1154-1160. 10.1109/TIA.2013.2251593 . hal-00949462

\section{HAL Id: hal-00949462 \\ https://hal.science/hal-00949462}

Submitted on 19 Feb 2014

HAL is a multi-disciplinary open access archive for the deposit and dissemination of scientific research documents, whether they are published or not. The documents may come from teaching and research institutions in France or abroad, or from public or private research centers.
L'archive ouverte pluridisciplinaire HAL, est destinée au dépôt et à la diffusion de documents scientifiques de niveau recherche, publiés ou non, émanant des établissements d'enseignement et de recherche français ou étrangers, des laboratoires publics ou privés. 


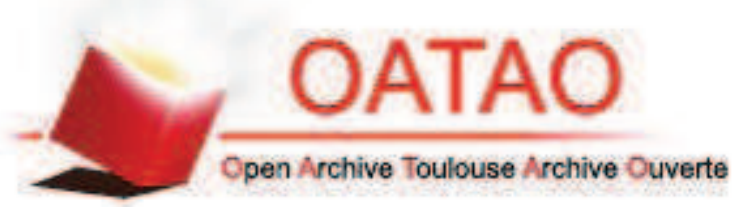

\section{Open Archive TOULOUSE Archive Ouverte (OATAO)}

OATAO is an open access repository that collects the work of Toulouse researchers and makes it freely available over the web where possible.

This is an author-deposited version published in : http://oatao.univ-toulouse.fr/ Eprints ID : 10970

To link to this article : DOI: 10.1109/TIA.2013.2251593

http://dx.doi.org/10.1109/TIA.2013.2251593

To cite this version : Toumi, Areski and Chhun, Labo and Bhosle, Sounil and Zissis, Georges and Maussion, Pascal and Baumann, Benedict and Wolff, M Acoustic Resonance Characterization and Numerical Model Including Acoustic Streaming in an HPS Lamp. (2013) IEEE Transactions on Industry Applications, vol. 49 ( $\left.\mathrm{n}^{\circ} 3\right)$. pp. 1154-1160. ISSN 0093-9994

Any correspondance concerning this service should be sent to the repository administrator: staff-oatao@,1istes-diff.inp-toulouse.fr 


\section{Acoustic Resonance Characterization and Numerical Model Including Acoustic Streaming in an HPS Lamp}

\author{
A. Toumi, L. Chhun, S. Bhosle, G. Zissis \\ and P. Maussion \\ Université de Toulouse; UPS-INPT; LAPLACE \\ (Laboratoire Plasma et Conversion d'Energie) \\ 118, route de Narbonne, F-31062 Toulouse cedex 9, \\ France \\ toumi@laplace.univ-tlse.fr
}

\author{
B. Baumann, M. Wolff \\ Hamburg University of Applied Sciences, Berliner Tor 21, \\ 20099 Hamburg, Germany
}

\begin{abstract}
This paper presents a numerical model of High Pressure Sodium (HPS) lamps including the acoustic streaming. The model is implemented in COMSOL and based on the finite elements method using a 2D axi-symmetric geometry. Moreover, a revision concerning AR experimental characterizations of HPS lamps will also be provided. The results presented in this paper will contribute to the understanding of $A R$ phenomena and help in the electronic ballast design methods for $A R$ avoidance.
\end{abstract}

Index Terms- AR characterization, Acoustic streaming, Acoustic waves, HPS lamps modeling

\section{INTRODUCTION}

High Pressure Sodium lamps (HPS) are artificial light sources based on the radiation of a sodium discharge. HPS are widely spread in our environment, especially in public lighting, where they can be recognized with their orange characteristic light color. Although lighting systems based on these lamps have currently one of the highest efficacy (typically $1201 \mathrm{~m} / \mathrm{W}$ ) higher efficacies can be achieved with high frequency power supply (some tens or hundreds of $\mathrm{kHz}$ ). However HPS lamps operation at high frequency is usually accompanied by a perturbing phenomenon, provoking lamp arc instability, known as Acoustic Resonance (AR) [1-2]. Nowadays, commonly used electronic ballasts for HPS lamps usually operate at low frequency (around a hundred hertz) square waves in order to avoid the occurrence of arc instabilities.

Using higher frequencies would decrease the ballast weight, size and cost. It was shown that the best operation frequency is around $300 \mathrm{kHz}$ [3]. Many attempts have been done to increase ballasts operating frequency while avoiding acoustic resonances. In [4] a modulation method based on a constant central frequency and a frequency modulation band of $10 \mathrm{kHz}$ was used. In [5], lamp geometry and operating frequency schemes are designed in order to reduce the negative effect of acoustic resonances. Another method referred to as 'spread spectrum' is also reported to reduce lamp instabilities when operated at high frequencies [6]. Lamp AR experimental characterizations are also conducted so as to define AR zones and its detections necessary for ballast design [7-9]. In [10] a model of HID lamp including the acoustic instabilities has been performed.

The Acoustic Resonance phenomenon is due to the development of standing acoustic waves in the lamp burner, however, the interaction between these acoustic waves and the arc is still poorly understood, especially their impact on the arc shape. Consequently, a model capable of taking into account this interaction is required in order to improve the phenomenon physical comprehension and evaluate the impact of acoustic resonances on arc distortion with the lamp frequency. In this paper, a revision of AR characterizations is conducted in section II. A model development of AR including acoustic streaming will be provided in the following sections. Contrary to [10], the physical phenomena of the HID lamp have been dissociated in order to see in precise manner the influence of each parameter (gaz pressure, burner geometry ...) on the behavior of the lamp under the influence of acoustic resonances. The results obtained with a 2D axi-symmetric HID lamp model will also be presented and discussed. This study will contribute to the understanding of AR phenomena and help in electronic ballast design methods for AR avoidance.

\section{AR EXPERIMENTAL CHARACTERIZATIONS}

Basically, the AR is excited when the power supply frequency is equal to the AR eigenfrequency and its power is higher than certain threshold. An example of experimental power supply for AR excitation is a low frequency square wave, superimposed with a high frequency sine wave current source. It should be noted that the AR can be different from lamp to lamp of the same type due to the geometry and gas composition tolerances in manufacturing process. Experimental results of power threshold in an HPS $150 \mathrm{~W}$ lamp are illustrated in Fig. 1 [11].

The study of an HPS lamp supply with a sinusoidal source also demonstrates that the degree of arc instability and lamp parameter variations due to AR depends on the supply 
frequency within the unstable $\mathrm{AR}$ zone (Fig. 2). This instability can also lead to lamp arc extinction. Furthermore, hysteresis phenomenon is presented in the discharge when lamp supply frequency sweeping is applied in increasing or decreasing direction. The experimental results given in Fig. 2 show that the AR zones and parameter variations are more pronounced in decreasing mode than in increasing mode. According to the explanation in [12], arc bending due to AR can shift the eigenfrequency, as a result, the extension of backward AR band is the consequence of frequency shifting.

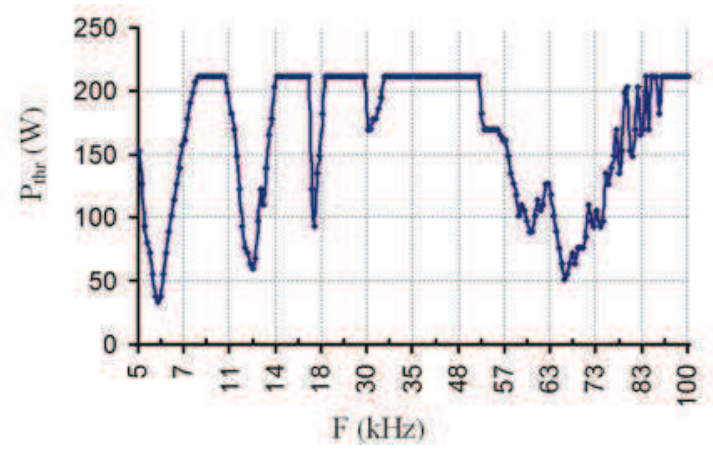

Fig. 1: AR threshold in HPS lamp SONT 150W [11]

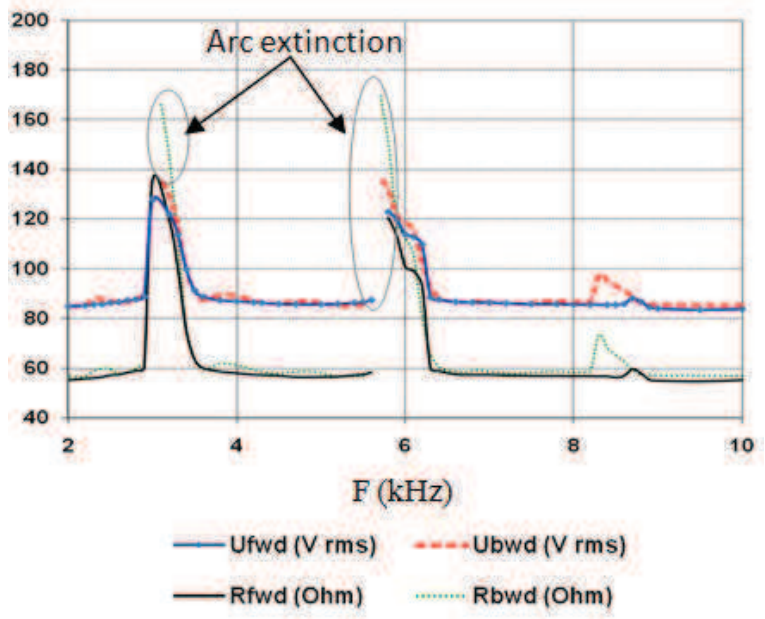

Fig. 2: Lamp electrical parameter variations in HPS lamp SONT 150W [11]

The AR excitation phenomenon is hence related to 3 main subjects: eigenfrequency, arc fluctuation amplitude and power threshold. The model for eigenfrequency estimations has been developed so far by many literatures while a simplified model can also be obtained. Besides, the model for AR instability or fluctuation amplitude at each AR mode is less developed because of the interaction between the AR and the arc is still less understood. In this paper, an AR modeling for arc fluctuation amplitude estimation, including the acoustic streaming is presented and will be discussed in the next section.

\section{MODEL DESCRIPTION}

\section{A. Lamp characteristics}

A typical HPS lamp characteristics and shape (Philips Master Son-T PIA Plus) used in our study are shown in Table I and Fig. 3 respectively. The filling gases within the lamp tube consist mainly of a mixture of sodium, mercury and xenon.

TABLE I BURNER DIMENSION AND PARTIAL PRESSURE OF THE FILLING GASES $[2$

\begin{tabular}{|l|l|}
\hline Radius $[\mathrm{mm}]$ & 2.4 \\
\hline Length $[\mathrm{mm}]$ & 76 \\
\hline Distance between electrodes $[\mathrm{mm}]$ & 58 \\
\hline DC current amplitude $[\mathrm{A}]$ & 1.82 \\
\hline $\mathrm{p}_{\mathrm{Na}}(\mathrm{kPa})$ & 12 \\
\hline $\mathrm{p}_{\mathrm{Hg}}(\mathrm{kPa})$ & 100 \\
\hline $\mathrm{p}_{\mathrm{Xe}}(\mathrm{kPa})$ & 30 \\
\hline
\end{tabular}
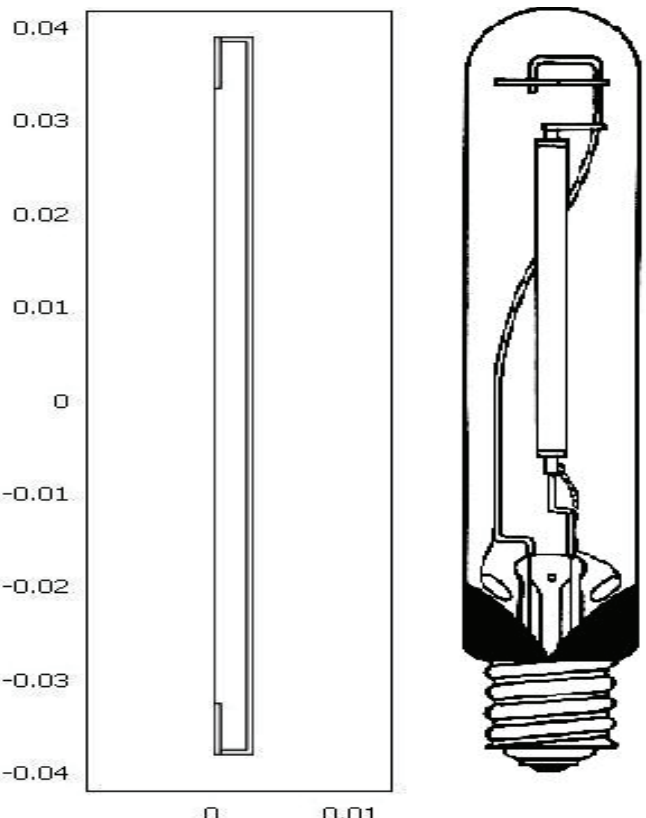

Fig. 3: Geometry of burner used in the model (burner dimensions in $\mathrm{m}$ )

\section{B. General assumptions}

The modeling of HID lamp is carried out under the following assumptions:

- the arc column is assumed to have a cylindrical symmetry,

- the plasma is supposed at the local thermodynamic equilibrium, under this assumption, the plasma properties can be deduced from the temperature distribution,

- the plasma flow is assumed incompressible,

- the coupling of the plasma with the electrodes is 
neglected,

The equations governing the physical gas discharge are resolved at steady state and the calculations are performed using the COMSOL Multiphysics Finites Element Method (FEM) tool.

\section{Fluid model}

According to the assumption mentioned above, the plasma mechanisms are governed by three differential equations:

- The Elenbaas-Heller equation for the determination of the temperature distribution in the burner,

- The incompressible Navier-Stokes equation to compute the convection velocity,

- The current continuity equation to obtain the distribution of the electrical field.

The Elenbaas-Heller equation (1) is written as follow:

$$
\vec{\nabla} \cdot(-\kappa \vec{\nabla} T)+\rho C_{p} \vec{U} \cdot \vec{\nabla} T=S_{t}
$$

where $k$ is the thermal conductivity, T the temperature, $\rho$ the mass density, $\mathrm{C}_{\mathrm{p}}$ the heat capacity at a constant pressure, $\vec{U}$ the natural convection velocity and $\mathrm{S}_{\mathrm{t}}$ the heat source density. The velocity $\vec{U}$ is set at zero in the electrodes and walls domains as there is no convection.

The term source $\mathrm{S}_{\mathrm{t}}$ is computed from

$$
S_{t}=\sigma E^{2}-u_{r a d}
$$

where $\sigma$ is the electrical conductivity, E the electrical field and $\mathrm{u}_{\mathrm{rad}}$ is the radiations losses.

Assuming an ideal gas medium, the mass density is given by

$$
\rho=\frac{p M}{R T}
$$

where $\mathrm{p}$ is the static pressure, $\mathrm{M}$ the average atomic mass of filling gases, $\mathrm{R}$ the ideal gas constant.

The boundary conditions of the external faces of the walls burner is specified according to

$$
\vec{n} \cdot k \vec{\nabla} T=q_{0}
$$

where $\mathrm{q}_{0}$ is the inward heat flux calculated from the StefanBoltzmann law

$$
q_{0}=-\sigma_{S B} T^{4}
$$

with $\sigma_{\mathrm{SB}}$ the Stefan-Boltzmann constant.

The temperature boundary condition are used for the external edges of the electrodes with a constant value of $\mathrm{T}_{0}=1500 \mathrm{~K}$. The initial value of the temperature is taken from [2] and is corresponding to the temperature profile of HPS lamp 400 W.

The velocity $U$ is given by the incompressible NavierStokes equation (6).

$$
\rho(\vec{U} \cdot \vec{\nabla}) \vec{U}=\vec{\nabla} \cdot\left[-p \vec{I}+\eta\left(\vec{\nabla} \vec{U}+(\vec{\nabla} U)^{T}\right)\right]+\vec{F}
$$

where $\vec{I}$ is the identity vector, $\vec{F}$ the volume force due to the gravitation $(\vec{F}=\rho \vec{g})$, and $\mu$ the dynamic viscosity. This equation is applied only to the domain corresponding to the plasma. As boundary conditions $\vec{U}=\overrightarrow{0}$ is used (no slip).

It is important to establish one point constraint for the pressure on the interior boundary. This point is placed at the vertices formed by the union of the lower electrode with the internal edge of the wall and its value is set at the static pressure of the lamp.

The initial value for this equation is $\vec{U}\left(t_{0}\right)=\overrightarrow{0}$ and $\vec{p}\left(t_{0}\right)$ is set at the static pressure of the lamp.

To obtain the electrical field $\mathrm{E}$ in the burner, the current continuity equation has to be solved (7) and it applies only in the plasma domain.

$$
\vec{\nabla} \cdot(-\sigma \vec{\nabla} V)=\nabla \cdot(\sigma E)=\nabla \cdot j=0
$$

where $\mathrm{V}$ is the electrostatic potential and $\mathrm{j}$ the current density.

The boundary conditions of the plasma domain are set as Neumann boundary conditions:

$$
\vec{n} \cdot(-\sigma \vec{\nabla} T)=J_{0}
$$

$\mathrm{J}_{0}$ represents the inward current density. Its value on the electrode tip is obtained by dividing the applied current by the transversal area of one electrode. The upper electrode tip is set at a positive value and the lower electrode tip at a negative value. The sides of the electrodes and the walls of the lamp are defined as the insulation condition $\left(\mathrm{J}_{0}=0\right)$. The initial value of the potential is set to $\mathrm{V}\left(\mathrm{t}_{0}\right)=0$.

The calculation of the transport coefficients is based on the work of Hirschfelder and al [13] and Devoto [14-15] according to the Chapman-Enskog theory. The plasma composition and the thermodynamic properties are obtained using the chemical equilibrium.

The radiation losses is taken from Elenbaas theory and is given by

$$
u_{\text {rad }}(T)=\sum_{i} N_{0}(T) \frac{g_{i}}{g_{0}} A_{i j}\left(E_{i}-E_{j}\right) \exp \left(-\frac{E_{i}}{k_{b} T}\right)
$$


where $\mathrm{N}_{0}(\mathrm{~T})$ is the atomic density in the lower states, $g_{\mathrm{i}}$ and $\mathrm{g}_{0}$ are the statistical weights of the excited and fundamental states, $\mathrm{A}_{\mathrm{ij}}$ the atomic transition probability and $\mathrm{k}_{\mathrm{b}}$ is the Boltzmann constant. The atomic transition for sodium is taken from [2], while neglected the influence of mercury and xenon on the radiation losses because its impact become only significant at temperature higher than $5000 \mathrm{~K}$. On the Fig.4(a), the temperature distribution is shown. We can see that the axial temperature is equal to $4400 \mathrm{~K}$ and it is in good agreement with the calculation of de Groot and van Vliet $\left(\mathrm{T}_{\mathrm{ax}}=4550 \mathrm{~K}\right)$ [2]. The convection velocity in burner, generated by the gravitational force $(\vec{F}=\rho \vec{g})$, is given by Fig.4(b). Because of this convection velocity, the arc discharge is maintained at the axis of the burner. The upward convective velocity in the centre of the arc tube is of the order of $0.1 \mathrm{~cm} / \mathrm{s}$.

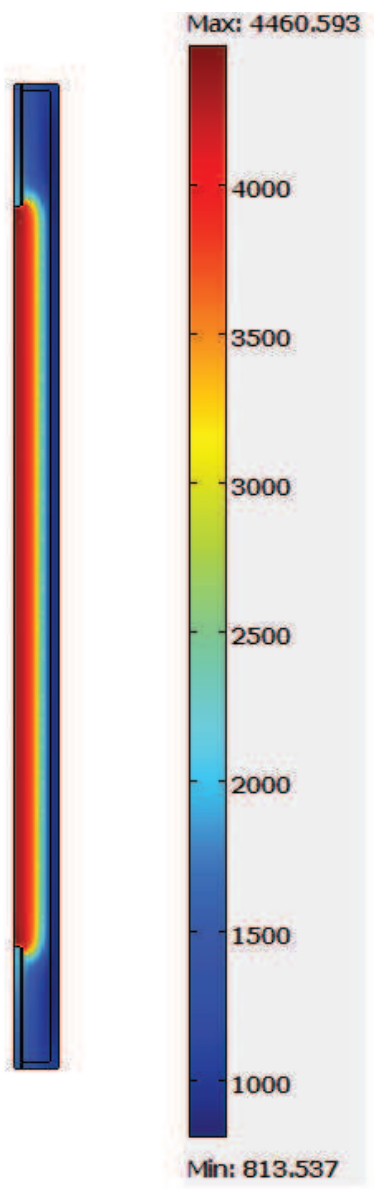

(a)

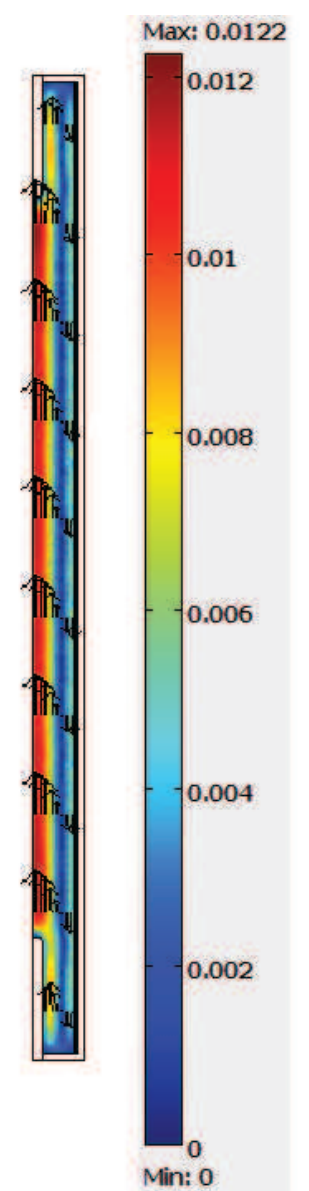

(b)

\section{Acoustic model}

When a high pressure discharge lamp operates at certain high frequencies, the discharge path can become unstable and distorted. These instabilities are due to the acoustic resonance generated by the propagation of an acoustic wave and its interaction with the discharge. The influence of acoustic resonances on the arc discharge becomes important when lamp power frequency is close to the corresponding $\mathrm{AR}$ eigenfrequency. The eigenvalue can be obtained by solving an inhomogeneous Helmholtz equation for the plasma domain $[4,17,18]$.

$$
\vec{\nabla}^{2} p+\frac{\omega^{2}}{c_{s}^{2}} p=i \omega \frac{\gamma-1}{c_{s}^{2}} H
$$

where $c_{\mathrm{s}}$ is the sound celerity of gas compound in the container, $\gamma$ denotes heat capacity ratio, and $\mathrm{H}$ constitutes the Fourier transform of the power density injected to the gas. The sound velocity $\mathrm{c}_{\mathrm{s}}$ and the temperature $\mathrm{T}$ are related through $c_{s}=\sqrt{\gamma R T / M}$

The inhomogeneous Helmholtz equation in (10) provides only the eigenfrequencies without the amplitudes of acoustic pressure because the term $\mathrm{H}$ is set to 0 . The model does not consider the absorption losses related to surface losses due to the thermal conductivity of burner's walls, and volume losses due to the friction in the plasma generated by the thermal conductivity and dynamic viscosity. In our simulation, we neglected the volumes.

\section{E. Post-treatment}

The amplitude is computed in post-treatment by introducing the quality factor. On the one hand, the quality factor $Q_{l}^{k}$ related to the conduction loss on the boundary layer with a depth $d_{l}^{k}$, and according to $[4,17,18]$ can be defined as in (11).

$$
Q_{l}^{k}=\frac{1}{2}(1-\gamma) \frac{d_{l}^{k}}{V_{b}} \int_{S_{b}}\left|p_{l}\right|^{2} d S
$$

$p_{l}$ denotes the acoustical eingenmode for $l$ th mode, $\mathrm{V}_{\mathrm{b}}$ the volume of the burner and $\mathrm{S}_{\mathrm{b}}$ its intern surface.

On the other hands, the quality factor $Q_{l}^{\mu}$ related to the viscosity loss term on the boundary layer described by a given depth $d_{l}^{\mu}$, is defined in $(12)[4,13,14]$.

$$
\frac{1}{Q_{l}^{\eta}}=\frac{1}{2}\left(\frac{\bar{c}_{s}}{\omega_{l}}\right)^{2} \frac{d_{l}^{\eta}}{V_{B}} \int_{S_{B}}\left|\vec{\nabla} p_{l}\right|^{2} d S
$$
Fig. $4:(a)$ The temperature profil $[\mathrm{K}]$ in the burner (b) and convection
velocity $[\mathrm{m} / \mathrm{s}]$ due to the gravitational force. The arrows denote the direction of the velocity.

The temperature distribution provides by this model is used as the input parameter for the computing of the acoustic modes in the next section. where $\vec{\nabla} p_{l}$ is the component of the pressure gradient tangential to the burner wall.

In order to compute the pressure amplitude for each 
acoustic mode without the losses, the following equation is applied $[4,17,18]$

$$
A_{j}=\frac{(\gamma-1)}{V_{B}} \int_{V_{B}} p_{j}^{*} \cdot I d V
$$

Finally, the AR amplitude in function of discharge injected frequency at a given AR frequency or AR mode is described by the following equation $[4,17,18]$ :

$$
A(\omega)=i \frac{A_{j} \omega}{\omega^{2}-\omega_{j}{ }^{2}+i \frac{\omega \omega_{j}}{Q_{j}}}
$$

with $\frac{1}{Q_{j}}=\frac{1}{Q_{l}^{k}}+\frac{1}{Q_{l}^{\eta}}$

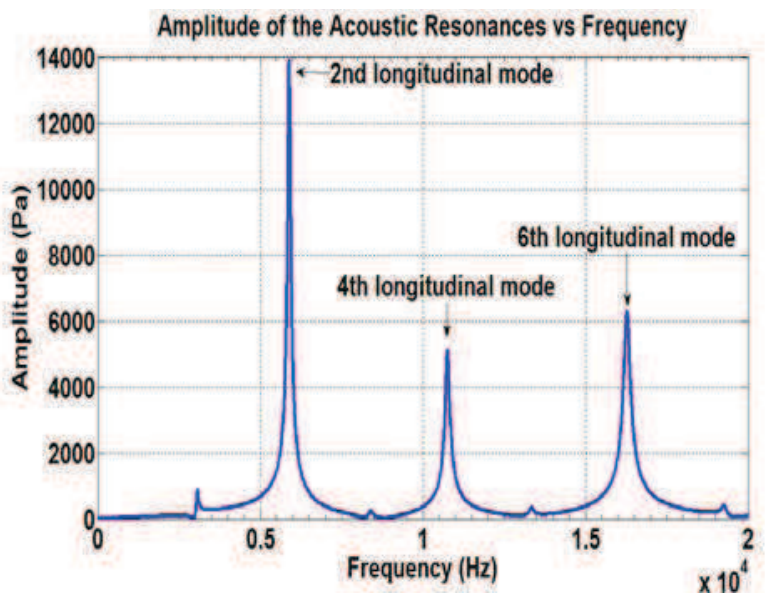

Fig. 5: Simulated acoustic resonances amplitude of HPS lamp SON-T

Fig.5 illustrates the simulation results of AR amplitude over input frequency in HPS lamp SON-T $150 \mathrm{~W}$ and it is in good agreement with the experimental results shown in Fig.1 and Fig.2. The frequency range in our study is defined as 20 $\mathrm{kHz}$, nevertheless, it is possible to simulate the model at higher frequencies. It can be seen that the maximums amplitudes of AR corresponds to the pair longitudinal modes. These results correspond to the experimental study of Epron [18] on HPS lamp SON-T $400 \mathrm{~W}$. Indeed, he denoted that only the pair modes appear in the sodium lamp when it supplied at high frequency. This is due to the integral pressure as shown on Fig. 6 and occurs in the computation of $A_{j}$ (13). Because the longitudinal pair mode of the acoustic pressure have a sine form with same positive and negative anti-nodes, as we can see on Fig.7, the effect of the positive and negative antinodes is vanished.

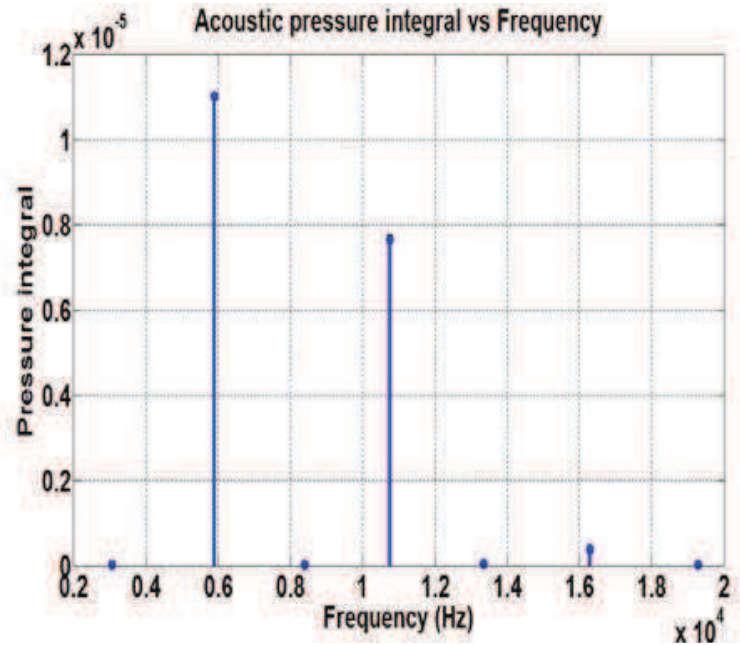

Fig. 6: Pressure integral versus resonance frequency

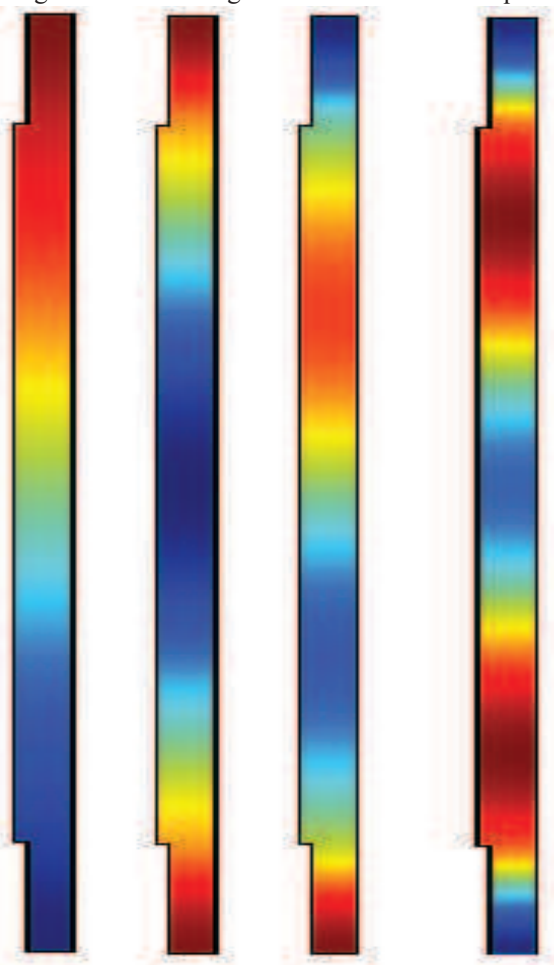

Fig. 7: Relative value of acoustic pressure for some modes (eigenfrequencies $3.06 \mathrm{kHz}, 5.9 \mathrm{kHz}, 8.4 \mathrm{kHz}$ and $10.8 \mathrm{kHz}$, respectively). Red indicates positive antinodes whereas blue indicates negative antinodes.

\section{F. Acoustic streaming model}

The acoustic streaming caused by the spatial variation of Reynolds stress by generating a net force per unit volume [19], and influences the behavior of the plasma in the burner of HID lamp. The study carried out by Afshar [20] on acoustic resonances considered its origin to the acoustic streaming. It was demonstrated that the acoustic streaming generates a non-linear acoustic flux with mean value different to zero. The force $F_{i \text { aco }}$ for an axe direction 'i', can 
be written as in (15):

$$
F_{i_{-} a c o}=-\frac{\partial \overline{\rho v_{i} v_{j}}}{\partial x_{j}}
$$

Meanwhile, for the axe direction ' $\mathrm{j}$ ', the corresponding force is described by:

$$
F_{j_{-} a c o}=-\frac{\partial \overline{\rho v_{i} v_{j}}}{\partial x_{i}}
$$

where $v_{i}$ and $v_{j}$ are the acoustic velocities following the direction of axes $\mathrm{i}$ and $\mathrm{j}$ computed by the inhomogeneous Helmholtz equation (10), and $\overline{\rho v_{i} v_{j}}$ is temporal average value.

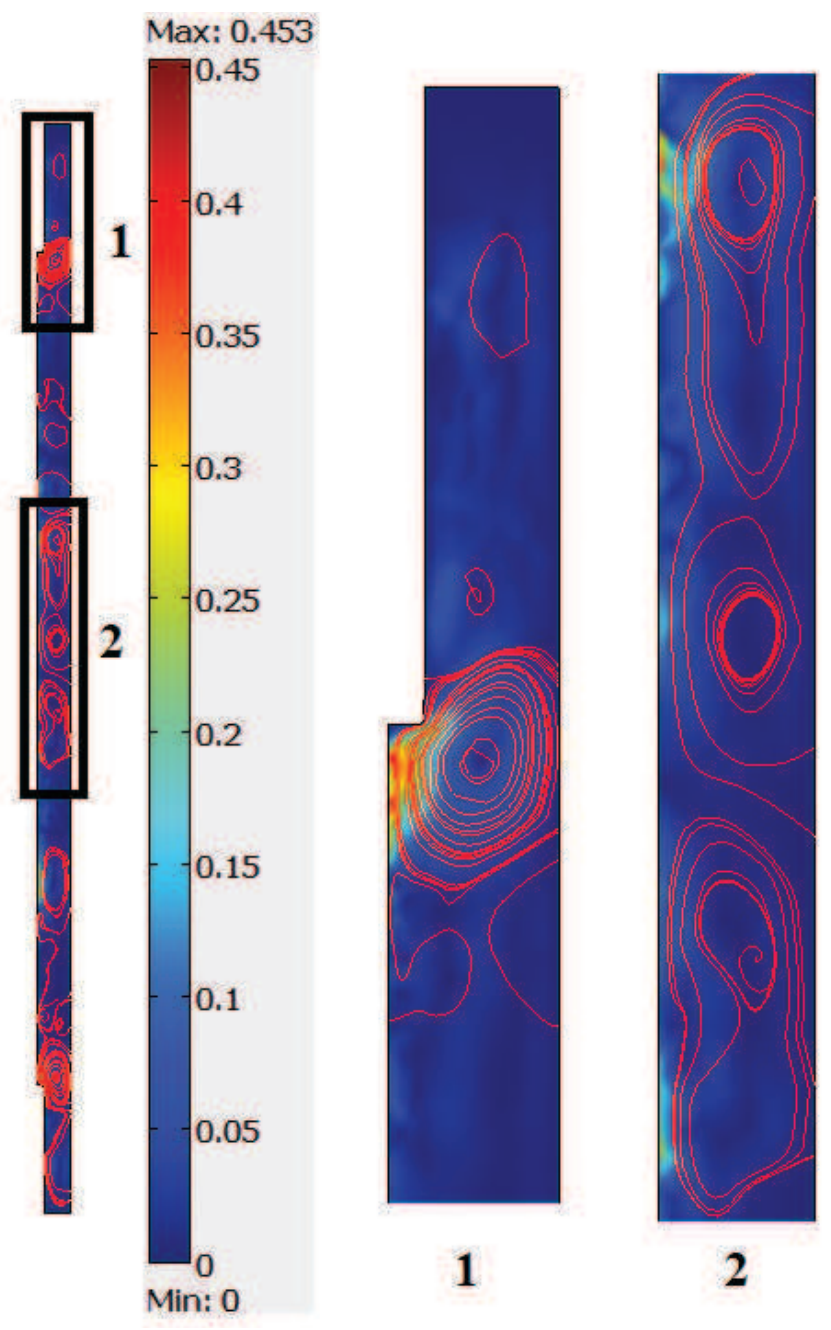

Fig. 8: The convection velocity $[\mathrm{m} / \mathrm{s}]$ including the influence of the acoustic streaming in HPS lamp SON-T $150 \mathrm{~W}$ and corresponding to the frequency equal to $10.8 \mathrm{kHz}$. The streamlines correspond to the velocity.
These calculated forces can be implemented in NavierStokes equation (6) to obtain the convection velocity meanwhile considering the gravitation and the acoustic streaming in the burner of the lamp:

$$
\begin{aligned}
& \vec{F}=\vec{F}_{i}+\vec{F}_{j} \\
& \vec{F}_{i}=\vec{F}_{i_{-} a c o} \\
& \vec{F}_{j}=-\rho \vec{g}+\vec{F}_{j_{-} a c o}
\end{aligned}
$$

These resulting forces representing the streaming phenomenon need to be integrated into the AR model given in previous section, in order to implement the numerical simulations.

On the Fig.8, we can see several fluxes of velocity generated by the acoustic streaming force. In addition of these fluxes, the amplitude of the velocity increases noticeably from $0.1 \mathrm{~cm} / \mathrm{s}$ (without AR) to $4.5 \mathrm{~cm} / \mathrm{s}$ (with AR) and it is non uniform like in the case where the acoustics resonances are not appear (Fig.4.b). This increasing of the amplitude and the generation of the velocity fluxes explain the instabilities in the burner of HPS lamp and the displacement of the electrical arc. Indeed, because of these fluxes, the arc discharge path it does not stabilized by the natural convection velocity like in the case where the lamp it is not under influence of the acoustic resonances.

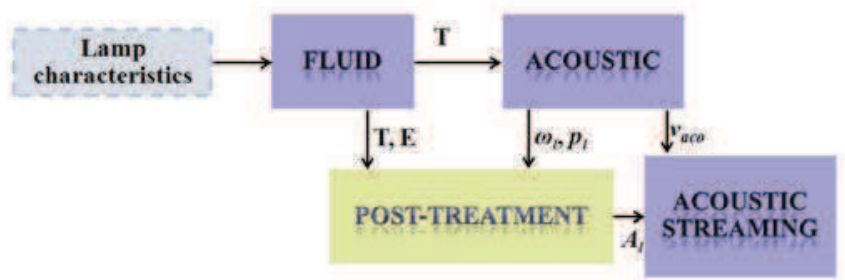

Fig. 9: Schematic modeling steps.

\section{CONCLUSION}

The revision of an AR experimental characterization method and the AR modeling including acoustic streaming are presented in this paper. The experimental results for AR excitation indicated different characteristics of lamp parameters responses during its $\mathrm{AR}$ excitation at high frequency. Whereas, the AR modeling is based on several coupled equations solved by Comsol finite element method considering 2D axi-symmetric discharge geometry. The simulated results allow to obtain a good estimation of AR eigenfrequency and amplitude. In addition, due to the introduction of acoustic streaming in our calculation, by taking in account the non-linearity of the acoustic velocity, it is possible to explain the interaction between the electrical arc in the burner of HPS lamps and acoustic resonances. 
Despites the simplifications and approximations, the model provides satisfactory results in relatively short computing time with reasonable memory requirement for a desktop computer.

\section{ACKNOWLEDGMENTS}

We are indebted to John Hirsch, from Philips Lighting, for his help on the realization of this work.

\section{REFERENCE}

[1] J.M. Davenport, and R.J. Petti, “Acoustic resonance phenomena in low wattage metal halide lamps" J. Illum Eng. Soc., pp. 633-642, 1985.

[2] J.J. de Groot and J.M. Van Vliet, "The high pressure sodium Lamp" Philips Technical Library, 1986.

[3] G. Trestman, "Minimizing Cost of HID Lamp Electronic Ballast", 28th Annual Conference of the Industrial Electronics Society, IEEE, 5-8 Nov. 2002, pp. 1214-1218.

[4] J. Hirsch , B. Baumann, M. Wolff, S. Bhosle, and R .Valdivia Barrietos, "Acoustic resonances in HID lamps : model and measurements" J. Appl. Phys.43,pp. 1-7, , 2010.

[5] S. Wada, A. Okada, and S. Morii "Study of HID lamps with reduced acoustic resonances", J. Illuminating Eng. Soc., pp. 162-175, 1987.

[6] R. van Honschooten, Philips Power Conversion Symp. Aachen, Germany, 2007.

[7] J. Olsen, and W.P. Moskowitz, "Optical Measurement of Acoustic Resonance Frequencies in HID lamps", IEEE $32^{\text {nd }}$ IAS annual meeting, New Orleans, USA, Oct 1997, pp. 2263-2269.

[8] J. Olsen and W.P. Moskowitz, "Time Resolved Measurements of HID Lamp Acoustic Frequency Spectra”, IEEE $33^{\text {rd }}$ IAS annual meeting, St Louis, USA, vol 3, 1998, pp. 2111-2116.

[9] J.C. Anton, C. Blanco, F. Ferrero, J. Viera, N. Bordel and G. Zissis "Acoustic Resonance Band detection Workbench for HID lamps", Industry Applications, IEEE Transactions on vol. 43, issue 5, 2007, pp. 1191-1198.

[10] T.D. Dreeben and G.P. Chini "Two-dimensional streaming flows in high-intensity discharge lamps", Phys. Fluids, vol. 23, issue 5, 2011, p. 14.

[11] L. Chhun, P. Maussion, S. Bhosle and G. Zissis," Characterization of Acoustic Resonance in a High Pressure Sodium Lamp", IAS IEEE transaction on issue 99,2011 .

[12] C. Juan, A. Alvarez, C. Blanco, J.F. Ferrero, J.C. Viera, N. Bordel, A. Martin, and G. Zissis, "An Acoustic Resonance Band Detection Workbench for HID Lamps”, Industry Applications, IEEE Transactions, vol 43, pp. 1191-1198, 2007.

[13] J.O. Hirschfelder, C.F. Curtis and R.B. Bird, "Molecular theory of gases and liquids", New York: Wiley, 1954.

[14] R.S. Devoto, "Transport Properties of ionized monatomic gases", Phys. Fluids, vol. 9, pp. 1230-1240, 1966.

[15] R.S. Devoto, "Simplified Expression for the transport properties of ionized monatomic gases", Phys. Fluids, vol. 10, pp. 2105-2112, 1967.

[16] B. Baumann, B. Kost, H. Groninga, and M. Wolff, "Eigenmode analysis of photoacoustic sensors via finite element method", Rev. Sci. Instrum., 77, 2006

[17] B. Baumann, M. Wolff, B. Kost and H. Groninga, "Finite element calculation of photoacoustic signals", Applied Optics, vol. 46, pp. 1120-112, 2007.

[18] S. Epron, "Etude et effet des oscillations acoustiques dans les lampes à décharges haute pression", Ph.D Thesis, Département Génie électrique, Univ. Paul Sabatier, Toulouse, 1999.

[19] J. Lighthill, "Acoustic streaming", Journal of Sound and Vibration. vol. 61(3), pp. 391-418, 1978.

[20] F. Afshar, "The Theory of Acoustic Resonance an Acoustic Instability in HID lamps," Leukos, 20(1), pp. 27-38, 2008. 